\title{
Innovation in Retail Process: From Consumers' Experience to Immersive Store Design
}

\author{
Eleonora Pantano', Giuseppe Laria²
}

\begin{abstract}
Due to the current advances in Information and Communication Technologies and consumers' increasing interest in entertaining and interactive retail environments, the sector of retailing is forced to pursuit innovation to maintain existing consumers and attract new ones. Especially the use of virtual reality techniques offers tools for supporting the design of innovative systems capable of enhancing this process. The aim of this paper is to integrate the consumers' experience in the development of innovation process for retailing. In particular, our findings highlight how the immersive technologies can be an efficient tool for pushing innovation in retailing. Therefore, the paper provides important issues for scholars and practitioners.
\end{abstract}

Keywords: technology management; innovation; virtual reality; retailing; consumer perception.

\footnotetext{
'Department of Business Science, University of Calabria, via P. Bucci, cubo 3B, 87036 Arcavacata di Rende-CS, Italy, 00390984492235. eleonora.pantano@unical.it

2Department of Linguistics, University of Calabria, via P. Bucci, cubo I7B, 87036 Arcavacata di Rende-CS, Italy, 00390984494363.

giuseppe.laria@unical.it
}

ISSN: 07 I8-2724. (http://www.jotmi.org)

Journal of Technology Management \& Innovation (C) Universidad Alberto Hurtado, Facultad de Economía y Negocios. 


\section{Introduction}

In recent years, there is a increasing interest in developing new tools for making the points of sale more attractive, in terms of store appealing, product displaying, facilities for consumers and so on (Pantano and Naccarato, 2010; Laria and Pantano, 20I I; Soderlund and Julander, 2009), as well as there is a increasing interest of consumers' towards the introduction of innovations in the traditional stores (Pantano and Viassone, in press), by representing an influencing factor for innovation process (Lubeck, R.M.,Wittmann, M.L., Battistella, L.F., 2012), which is strictly linked to customers' preference (Olsen and Velo, 20I I). For this reason, literature shows a great deal of research in the development of the best practices and tools for exploiting consumers' information in the innovation process (Olsen and Velo, 20I I; Fuller, J., Hutter, K., Faullant, R., 20II). Although developing new products and services is a compulsory element for business profitability (Jugend and da Silva, 20 I2; Sanchez, et al., 20I I), these tools are mainly used for the development of new products, whereas there is still a lack on the consumers' successful involvement for improving processes such as retailing or points of sale. Therefore, firms are forced to innovate to maintain existing consumers and attract new ones.

Due to the current advances in Information and Communication Technologies, the sector of retailing is forced to pursuit innovation from the most recent technical solutions. Especially the use of virtual reality techniques offers tools for supporting the design of innovative systems capable of enhancing users' experience (Korves and Loftus, 2000). In fact, they have been largely exploited to design factor layout for (a) creating virtual objects, (b) placing them in the virtual environment with the related properties such as lights and illumination, and (c) testing the obtained results before the actual realization (Korves and Loftus, 2000; Iqbal and Hashmi, 200 I; Lee, J., Han, S.,Yang., J., 20I I).

Hence, this study aims to integrate the consumers' experience in the development of innovation process for retailing, through the exploitation of the most advanced 3D virtual reality tools, by providing a useful framework for its design. This study involves a qualitative analysis which makes consumers' point of view emerge for examining dimension of store aesthetic and related influence on consumer' affective changes in terms of satisfaction and arousal, and on their emotional responses in terms of perceived store quality. Our findings highlight how the immersive technologies can be an efficient tool for pushing innovation in retailing.

The first part of the paper is related to the analysis of the basic features of virtual stores supported by 3D graphics and of the consumers' acceptance, whereas the second one deepens our knowledge on consumers' response towards a new immersive store and proposes an innovative approach for the design of an innovative and efficient one.

\section{Theoretical Background}

\section{Virtual reality for innovative stores}

Previous researches identified the increasing interest for e-commerce and web-based channel for shopping (Hsiao, 2009; Liu and Forsythe, 20I I) with a subsequent decreasing interest for traditional stores (Rotemi-Mindali and Solomon, 2007; Weltevreden, 2007; Hsiao, 2009). Hence, traditional points of sale are forced to innovate to catch consumers' interest, for maintaining the existing market share and exploring new market opportunities.

As anticipated by Smith and Heim in 1999, store environments might benefits from the exploitation of virtual reality tools in order to provide a wider set of efficient information for supporting the decision-making process. In particular, virtual reality techniques allow creating innovative web-based stores, enriched with interactive interfaces include hyperlinks, graphic icons, several contents (such as audio, video, texts), 3D images and provide novel modalities for supporting the human-computer interaction (Lee and Chung, 2008; Algharabat and Dennis, 2010). Hence, these new digital environments show the features of interactivity, presence and immersion (Lee and Chung, 2008). While interactivity refers to the possibility for users to modify, move and touch the objects available in the environment in real time; presence refers to the users feeling of being in the virtual environment; and immersion refers to the feeling of being surrounded by the digital landscape. Furthermore, factors as store layout and atmosphere play a similar role both in the offline and online retail context (Mummalaneni, 2005). These technologies make the virtual store more appealing and attractive, with consequences for the store choice.

\section{Basic features of virtual stores}

Currently, virtual reality is successfully applied to e-commerce and e-tailing, by providing efficient digital models for objects, salesperson, appealing environments capable of creating impressive virtual stores (Jin, 2009; Lee and Chung, 2008).

According to Katerattanakul and Siau (2003), the image of these stores is mainly based on the system facilities (i.e. fast system response and secure transactions), product variety and related information, convenience (in terms of navigability efficiency and location indicator), as well as on a pleasant and attractive graphic design. In fact, a high aesthetic appeal of a virtual store might result in high pleasure for users. The store environment, which includes various stimuli in the of- 
fline context such as colour, sound, scent, layout and space, affects consumer perception of store image and his/her expectations toward the merchandise (Oh, et al., 2008). In the online context, the products are displayed in a more attractive way which is influenced by a favourable store design (Bauer,J. C., Kotouc,A.J., Rudolph,T., in press.; Oh et al., 2008; Vieira, 2010), as well as the virtual attractiveness of these stores is influenced by the aesthetic appealing (Wang, 20I I; Vieira, 20I0). Moreover, the 3D virtual products enrich the provided information and involve and enjoy more consumers during the shopping experience (Kim, J., Fiore,A. M., Lee, H.-H., 2007).

The visual aesthetic influences consumer' perception, by providing a symbolic function which affects the store evaluation and store judgments of store brand quality (Vieira, 2010 ), thus, the virtual reality techniques become key factors for designing an effective virtual store. The virtual store design is related to the consumer evaluation of the atmosphere aesthetic, with benefits on loyalty towards the store/ brand, satisfaction and total expenditure (Vieira, 20l0).

The virtual storefront of these e-stores represents the physical shop window in the e-context (Oh et al., 2009). As a consequence, a great deal of research is paid to understand the most effective modalities to present both product and related information through an appealing design, and an effective storefront layout.

For instance, Vrechopoulos et al. (2004) proposed some practice for the development of an efficient virtual store layout. From their experiment consumer's preference for a virtual grocery store with a hierarchical/tree structure emerges, which represents the easiest structure to navigate. Furthermore, consumers seem to appreciate the search function that allows reaching any place easily. This layout is also considered the most entertaining one and contributes to increase consumer's perceived entertainment. Hence, an increasing attention to the high arousal environment positively influences consumers' satisfaction and consumer loyalty toward the store if compared to the contexts with a low arousal atmosphere (Vieira, 20I0).

Since the virtual attractiveness is positively associated to the provided fun and enjoyment influences on consumers' perception (Soderlund and Julander, 2009; Pantano and Naccarato, 2010), marketers would take into account the possibility to provide entertaining tools for the development of a more efficient store. As a consequence, there is an increasing attention towards the visual store aesthetic than towards the products (Vieira, 2010).

Although the great deal of research in developing new tools for making the traditional stores more attractive (Pantano and Naccarato, 2010; Pantano and Corvello, 2010), the research on the integration of $3 \mathrm{D}$ virtual techniques in the point of sales is still in progress. In fact, just few recent studies focused in this direction by proposing the concept of immersive store (Laria and Pantano, 20I I) with the involvement of a limited number of consumers in order to understand their response toward the introduction and usage of the technology.

\section{Consumer acceptance of virtual store}

Since the increasing importance of virtual stores and their influence on shopping mode choice and purchasing decision (Oh et al., 2009; $\mathrm{Ha}$ and Stoel, 20l0), understanding consumer' acceptance of these stores is emerging as a new hot topic.

To date, most of the studies investigated consumers' response toward the choice of virtual stores by focusing on the Technology Acceptance Model (Davis, 1989), in order to predict their attitude toward accepting the new store. This model is based on the key constructs of perceived ease of use (the degree to which a person believes that using the technology will be free of effort), perceived usefulness (the degree to which a person believes that using the technology improves his/her performance), attitude (person assessment toward the technology) and behavioural intention (the degree to which a person will perform a certain behaviour). Some researches (Oh et al., 2009; Chen and Tan, 2004) carried out that playfulness/enjoyment, information quality and trust affect a positive consumer attitude, by extending the traditional TAM. In fact, enjoyment can be considered by consumers as a motivational factor for the choice of the virtual store for their purchases.

The information quality reduces the risk related to a context featured by a lack of interaction with shopping assistants such as in e-tailing (Tsai and Yeh, 2010). Thus, the provided information must be ease to find, rich and reliable (Udo, G. J., Bagchi, K. K., Kirs, P. J., 2010; Kang and Lee, 2010; Oh et al., 2009). To achieve this goal, the virtual store would exploit several communication channels, which support consumers to experience the product as in the real context, to make comparisons among products, and to increase the trust in the technologies. In fact, in e-tailing consumer is unable to physically examine products and interact with vendor, thus his/her judgements toward the usage of this technologies are influenced by the trust in the virtual shopping environment (Chiu, C.-M., Huang, H.Y., Yen, C.-H., 20I0). As a consequence, an efficient virtual store must overcome the uncertainty and sense of risk involved in the experience with the virtual store. Furthermore, the virtual shelves avoid the problems concerning the shelf-based scarcity (Parker and Lehmann, 20II), by displaying a larger amount of goods if

ISSN: 07 I8-2724. (http://www.jotmi.org)

Journal of Technology Management \& Innovation (C) Universidad Alberto Hurtado, Facultad de Economía y Negocios. 
compared to the traditional offline ones. Despite this increasing attention to the importance of visual appearance, as well as to the development of more effective virtual stores, there is still a lack of studies concerning how it is possible to integrate current advances in $3 \mathrm{D}$ graphics and immersive technologies for developing innovative appealing real stores and how consumer are willing to accept these one for living new shopping experiences capable of supporting and influencing their decision-making process.

\section{The innovative immersive store}

The 3D virtual store is based on the current advances in computer graphics as well as in low-cost hardware. The immersive store proposed in the current study reproduces a customizable two-floor environment with the basic features usually available in any store, such as shelves and pavilions. In particular, it has been realized to be easy adapted to several points of sale, thus it is currently devoid of objects and characteristics that fit the environment into a particular category (i.e. grocery).

The store has been modelled from the basic planimetric map in order to achieve an efficient stereoscopic (immersive) 3D real-time simulation which allows to explore the environment as a physical one. Attention has paid to the reproduction of objects by focusing on material, colour, lighting in order to create the best mix of conditions capable of enhancing the perception of the virtual environment and the feeling of immersion.

To achieve this task, the system has been developed through the use of stereoscopic techniques. These are based on the digital scenario (represented by the 3D virtual reconstructions of products and furniture) and the real one (represented by the real consumers who explore the digital environment (Laria and Pantano, 20II). Hence, the final system consists of two projectors and a computer (which combines two different images of the same object) provided by the provided by the projectors, in order to enhance the feeling of immersion in the 3D scenario (Laria and Pantano, 20I I), as presented in Figure I.

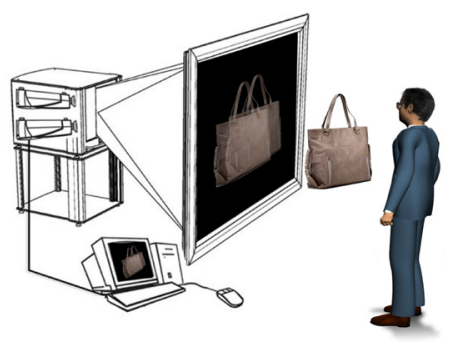

Figure I: Immersive system functioning.

\section{Environment architecture}

The store environment was modelled on a two-floor shop, where the objects were created from standard primitives and subsequently improved through refinement tools. In this way, the modelling achieves a good result with the lowest number of required polygons and to keep the maximum control on the 3D object topology, with emphasis on the basic features of materials and surfaces in order to define the virtual material of each object. Subsequently, material features, lighting properties and colour were defined. In particular, we defined the visual effects such as transparency, reflections or bump mapping setting up multi textured layered materials, as well as the lights and camera. In particular, we added some particular features such as transparent stairs, an elevator, and few booths in order to create partitions, shelves and corridors which user can explore as in a physical store (Figure 2). In this way, the scene is ready to be loaded in the stereoscopic view, by setting the variables that control the stereoscopic separation and the focus. The real-time application was developed using Quest3D software that allows programming the whole environment behaviour through a building-blocks paradigm. In fact, this software supports the setup of stereoscopic view in horizontal, vertical split or anaglyph mode.

The final simulation prototype was exported as an executable file automatically starting at $2048 \times 768$ horizontal split resolution.

The final model is presented in Figure 2, which shows what consumers visualize while exploring the immersive store.

The image on the left represents the view from the second floor which includes the booths, pylons and benches; whereas the one on the right is related to a corner of the first floor with some counters with shelves for the items on sale and a bar angle included in a virtual relaxing area.

In this step of the research, the stores does not show available products, it represents only the structure of the store which will be improved according to consumers' response. Meanwhile, this structure can be easily adapted to a wide range of products, which can be added through the insertion of other virtual models (equipped with information such as price, colour, etc.) to the database of products that will be introduced in the retail system.

\section{Consumer-system interaction}

The interaction modalities have been developed in order to provide users the possibility to explore the store as realistic as possible. The aim was to plan a graphical interface capable of providing needed information in the simplest pos-

ISSN: 07 I8-2724. (http://www.jotmi.org)

Journal of Technology Management \& Innovation (C) Universidad Alberto Hurtado, Facultad de Economía y Negocios. 


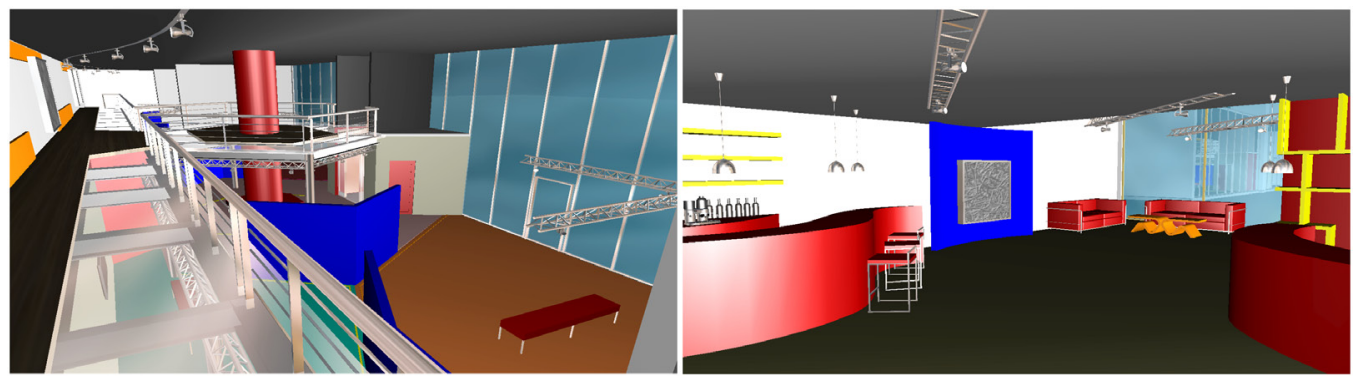

Figure 2:Two views of the immersive store.

sible way by putting high affordance in the interaction model. To achieve this task, a joystick with pointer function such as Wii-mote represents the main input device, which supports the interaction with the environment. In fact, through this device the consumer has the possibility to explore and retrieve information in an easy way avoiding a long set-up preparation such as wearing some unhandy device or heavy head mounted displays before beginning the exploration. Thus, consumer may access to the shopping experience in the sore by wearing polarized glasses and picking up the joystick, with high freedom of movements throughout the virtual space. In this way, he/she is able to walk by using directional buttons and perform different actions such as activate elevators, enlarge datasheets referring to items, or complete his/her purchasing operations by pointing at the interface layout component with the joystick and pressing the action button.

In addition, during the exploration consumer would pay attention to the available items and retrieve information by opening datasheets that are displayed on the HUD through the paradigm of viewport space layout (Polys, N. F., Kim, S., Bowman, D. A., 2006). In this way, the labels referring to a particular product is displayed in a $2 \mathrm{D}$ viewport and connected to the object with lines extending into the space. Once the exploration phase is over, consumer can reach the payment area for checking his/her chart and perform all the operations needed to conclude the purchase.

\section{Methodology of research}

The research aims at proposing an innovative immersive store, by providing a framework for its design based on a consumer-centered approach, in order to involve consumers in the design of the final service and enhance their trust in the retailer (Niininen et al., 2007). To achieve this goal, the study investigates the perceptual and cognitive provided by this technology. Hence, the research questions are the following:

RQI:Which is the impact of immersive store on consumers' retail process, in terms of store, products, quality of shopping experience?

RQ2:Why immersive store matter for innovating with consumers in the retail context?

RQ3: How do immersive stores reply to consumers' need of innovativeness?

Participants and data collection

To attend the experiment, the present research involved 36 subjects ( 12 males and 24 females), recruited at University of Calabria (Italy), between March and May 2012. The demographic characteristics of the sample are based on age, education, knowledge of virtual reality and interest in new technologies (Table I).

\begin{tabular}{|l|l|}
\hline Gender & Percentage \\
\hline Male & $33 \%$ \\
\hline Female & $67 \%$ \\
\hline Age & \\
\hline Less than 25 years & $53 \%$ \\
\hline Between 26 and 35 years & $38 \%$ \\
\hline More than 35 years & $9 \%$ \\
\hline Education & \\
\hline High school & $22 \%$ \\
\hline Master Science & $61 \%$ \\
\hline PhD/Specialization & $17 \%$ \\
\hline Knowledge of virtual reality & \\
\hline No knowledge & $33 \%$ \\
\hline Sufficient knowledge & $47 \%$ \\
\hline Good knowledge & $20 \%$ \\
\hline Interest in new technologies & \\
\hline No interest & $8 \%$ \\
\hline Sufficient interest & $25 \%$ \\
\hline Good interest & $67 \%$ \\
\hline
\end{tabular}

Table I. Sample demographic characteristics.

ISSN: 07I 8-2724. (http://www.jotmi.org)

Journal of Technology Management \& Innovation (c) Universidad Alberto Hurtado, Facultad de Economía y Negocios. 
A noteworthy characteristic is related to the age (the $53 \%$ less than 25 years) and to the large interest of participants in the new technologies. Another important finding is related to the knowledge of virtual reality, which is considered sufficient by the most of participant, whereas the $20 \%$ declared a good knowledge and only the $8 \%$ no knowledge of virtual reality.

All participants attended the experiment by browsing the immersive store. The environment was identical for everyone, but each participant could choice his/her own path, as well as the visit duration (no time constraints were defined for the experiment). Upon completion of this visit, they were asked to answer a questionnaire with open-ended questions in order to allow the user's opinion to emerge, which has been evaluated through the MaxQda software for the content analysis.

\section{Key findings}

Several factors emerged from interviews and have been coded and loaded through MaxQda in order to identify the most frequent ones. In particular, 13 factors/codes has been identified, with the constraint to appear in no more than once in each interview. Table 2 summarizes the factors/ codes with the related frequency:

The most frequent code is related to the pleasure emerged by the experience in the new store, which seems to be a motivating element for the choice of this store for future purchases. In fact, most of users appreciated the novelty and interactivity of the immersive store, as well as the possibility to explore the store and the available products without other consumers who usually generate traffic in traditional small environments. In fact, a respondent said: "I hate the

Table 2. Codes frequency.

\begin{tabular}{|c|c|c|}
\hline Codes & Description & Frequency \\
\hline More info & $\begin{array}{l}\text { Users suggest adding more informa- } \\
\text { tion to each available product usu- } \\
\text { ally not available in the traditional } \\
\text { point of sale (i.e. video, info on the } \\
\text { manufacturing process, etc.). }\end{array}$ & 4 \\
\hline No walls & $\begin{array}{l}\text { Users suggest removing the inner } \\
\text { walls in order to create one bigger } \\
\text { open space. }\end{array}$ & 5 \\
\hline Enlarge & $\begin{array}{l}\text { Since the new store has not space } \\
\text { constraints, users suggest enlarging } \\
\text { the proposed environment. }\end{array}$ & 6 \\
\hline New experience & $\begin{array}{l}\text { Users lived a new and amusing ex- } \\
\text { perience in the immersive store. }\end{array}$ & 6 \\
\hline Add plants/products/... & $\begin{array}{l}\text { Since the new store has not space } \\
\text { constraints, users suggest adding } \\
\text { plants, products and furniture to the } \\
\text { proposed environment, in order to } \\
\text { make the store more attractive and } \\
\text { "real". }\end{array}$ & 6 \\
\hline
\end{tabular}

ISSN: 07 I8-2724. (http://www.jotmi.org) 
Relaxing

More products

Interesting

Comfortable

Amusing

Big room

Clothing

Like it
Users consider the store relaxing.

The virtual presence of sofas and a corner for a bar contributes to this feeling.

Users suggest increasing the number of available product, in order to display a wider range of products if compared to the traditional points of sale and fill all the blanks in the current environment.

Users consider the experience in the new store very interesting.

Users find the store relaxing due to the virtual presence of sofas and a 8 corner with a café.

Users affirm to live an amusing experience in the new store.

Users appreciate the dimension of the store, which seems to be larger

than the traditional ones.

Users would like to buy clothes in the new store.

Users appreciate the new store and affirm that they'd prefer it for their purchases. According to their opinion, this store seems to be more appealing than a traditional one. crowd people in the stores. I can't see what I would. I can't take my time for my purchases!". Other important codes concern the suggestions proposed by users to improve the immersive store such as the possibility to enlarge the room or to add more products and furniture. These data are further confirmed by the match between each code and respondent, which represents in detail the code distribution among users. Table 3 summarizes this match, where columns represent single code, and rows represent the single interviewed. Since the codes have been loaded in order to appear at most once in each interview, the value of each match is I if there is the match, 0 otherwise.

A subsequent analysis has been conducted in order to investigate to what extend the codes are related each other.This analysis involves also the demographic variables (gender, age, education, knowledge of virtual reality, and interest towards new technologies), in order to understand if variables such as the knowledge of the involved techniques might influence the perception of the new store. From the analysis the most 
Table 3: Matrix of correlation between code and respondent.

\begin{tabular}{|c|c|c|c|c|c|c|c|c|c|c|c|c|c|c|}
\hline & 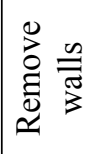 & 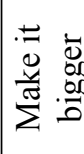 & 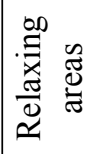 & 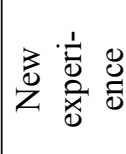 & 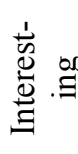 & 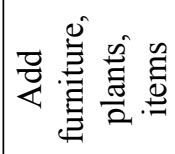 & 咅 & 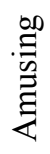 & 宅 总 & $\begin{array}{l}:= \\
0 \\
.0 \\
.7\end{array}$ & .00 & 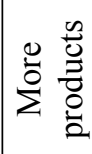 & $\begin{array}{l}00 \\
. \\
\equiv \\
0 \\
0 \\
0\end{array}$ & $\begin{array}{l}n \\
0 \\
0 \\
0\end{array}$ \\
\hline$\# 1$ & & & & & & & & & 1 & 1 & 1 & 1 & 1 & 1 \\
\hline$\# 2$ & & & & & & & & 1 & 1 & 1 & & & & 1 \\
\hline$\# 3$ & & & & & & 1 & 1 & 1 & & 1 & & 1 & 1 & 1 \\
\hline$\# 4$ & & & & & 1 & & 1 & & 1 & 1 & 1 & & & 1 \\
\hline$\# 5$ & & & & & & & & & & 1 & & & & 1 \\
\hline$\# 6$ & & & & 1 & & & & & & 1 & & & & 1 \\
\hline$\# 7$ & & & & & 1 & & & & 1 & & & & 1 & \\
\hline$\# 8$ & & & & & & 1 & 1 & 1 & & 1 & 1 & 1 & & \\
\hline$\# 9$ & & & & & & & 1 & 1 & & 1 & & & & \\
\hline$\# 10$ & & & & & & & 1 & 1 & & 1 & & & & \\
\hline \#11 & & & 1 & & 1 & 1 & & & & 1 & & & 1 & \\
\hline \#12 & & & & 1 & & & & & & 1 & 1 & 1 & 1 & \\
\hline \#13 & & & & & & & & & & 1 & 1 & & & 1 \\
\hline \#14 & & & 1 & & & & & & & & 1 & & 1 & 1 \\
\hline \#15 & & & & & 1 & & & 1 & & 1 & 1 & & 1 & \\
\hline \#16 & & 1 & 1 & & & & & & & 1 & & & 1 & \\
\hline \#17 & & & 1 & & & & & & & 1 & & & & \\
\hline \#18 & & 1 & & 1 & & & & & & & & & 1 & \\
\hline \#19 & & & & & & & & 1 & & & & & & 1 \\
\hline$\# 20$ & & & & & & 1 & 1 & 1 & & & & 1 & & \\
\hline$\# 21$ & 1 & & 1 & & & & & & & & 1 & & & \\
\hline$\# 22$ & 1 & & & & & & & & & & & & 1 & \\
\hline \#23 & & & & 1 & 1 & & & & & 1 & & 1 & & \\
\hline \#24 & 1 & & & 1 & & & & & & 1 & & & 1 & 1 \\
\hline$\# 25$ & & & & & & & 1 & & & 1 & 1 & & & 1 \\
\hline \#26 & 1 & 1 & & & & & & & & & & & & \\
\hline$\# 27$ & & & & & & & & 1 & & 1 & 1 & & & 1 \\
\hline \#28 & & & & & & & & 1 & & & 1 & & & 1 \\
\hline \#29 & & & & & & & 1 & & & 1 & 1 & & 1 & \\
\hline$\# 30$ & & & 1 & & & 1 & & & & 1 & & 1 & 1 & \\
\hline \#31 & 1 & 1 & & & 1 & & & & & 1 & & & 1 & 1 \\
\hline \#32 & & 1 & & 1 & & & & & & 1 & & & & \\
\hline \#33 & & 1 & & & & & & & & 1 & & & & \\
\hline \#34 & & & & & & 1 & & 1 & & 1 & & 1 & & \\
\hline \#35 & & & & & 1 & & & & & & & 1 & & \\
\hline
\end{tabular}


used couple appear 4 times, thus four respondents have used the same coupe of adjectives for describing the system. In order to give more emphasis to the couples of codes with higher weight, the ones that appear in less than 2 interviews have been ignored.

The most used couple of codes appears 4 time and represent the match between big room and comfortable, thus 4 respondents who appreciated the wide space of the environment considered it also relaxing. The couple relaxing and like it appears is 3 interviews as well as the couple more products and like it. Hence, 3 respondents who appreciated the new store appreciated also the relaxing atmosphere and suggested to increase the number of product on sale. In addition, the couple more products and big room appears in 2 interviews, thus 2 respondents who appreciated the wide space suggested to use it for a wider products exposure, by exploiting the wider space for products displaying provided by the environment.

As emerged from the analysis, the demographic factor do not play a remarkable role in the perception and choice of the new store.

\section{Discussion}

This study shows the increasing interest of consumers in innovation for retailing, in accordance with previous studies (Pantano and Viassone, Olsen and Velo, 20I I). This study offers a new tool for exploiting consumers' information for the innovation process in order to develop new systems highly accepted by final users who are actively involved in the design process. Then go on to discuss the implications of the results. It is also important to discuss how the results relate to the literature you cited in the introduction. In other words, emphasize any theoretical consequences of the results.

Furthermore, the results of the experiment suggest that the immersive store influences consumer' perception of the point of sale and might be a motivating factor for the choice of the store. Although the visit of the immersive store was simulated in a laboratory with no real salespersons, the perception of the innovativeness prompted consumers to consider a different evaluation of the firm and of the products, with benefits for the business profitability.

In particular, respondents suggested introducing this system for clothing, in opposite with the preliminary idea to use it for furniture, cars and other products that need wider spaces. In fact, the environment perception effects consistently mediate consumers' evaluation of the products.

Across the experiment, we found that users attention has been caught by the sofas and café that provided a feeling of relax and comfort. Thus, consumers considered the store a good place for both purchasing and having fun. In fact, they appreciated the new and amusing experience, by commenting "exploring this store is more exciting than a traditional one", and "l'd prefer this store more for having fun than for purchasing". These findings are consistent with other previous studies that have shown that an entertaining retail context positively affects consumer's shopping behaviour (Soderlund and Julander, 2009; Pantano and Naccarato, 2010).

Furthermore, users appreciated the new idea of the store, which seems to be more "futuristic" and "devoted to modernity and new technologies", as a respondent affirmed. In fact, also users who have no knowledge of virtual reality and no interest in the advanced technologies appreciated this environment for their purchases. As a consequence, also consumers who usually consider boring the shopping activity may be motivate to visit this kind of store.

In addition, in this store consumers expect to find more detailed information on available products, which can be accessed to further link to videos, photos, in order to support the decision process. The possibility to choose the visualized information enhances the customer rapport building and predisposes higher purchase intentions (Schlosser and Shavitt, 2009), with benefits for the trust in retailer (Niininen, O., Buhalis, D., March, R., 2007).

Since the structure of the virtual store is flexible (it can be easily modified and implemented), it might be easily adapted to different product categories. Furthermore, it avoids the problem connected to the shelf-based scarcity (Parker and Lehmann, 20II), by displaying each products available, organized for colours, sizes, etc.. In fact, the 3D products are reproduced including real colours and flashes that can be easily controlled by consumers in order to live a more realistic experience, as anticipated by Algharabat and Dennis (2010) and Kim, J., Fiore, A. M., Lee, H.-H. (2007). In this way, products are always available with no time constraints or social pressure for making decision. Since consumers prefer a store with well organized shelves which offer a large amount of available goods and they perceive more positively a store which display a wider range of products, these technologies improve the products' display in terms of assortment presentation, as well as the organization of the product which make the searching and finding more fast and easy, in accordance with (Bauer, J. C., Kotouc, A. J., Rudolph, T., in press.).

According to consumers' suggestions, it is possible to improving the immersive store, by designing a new one that retailers can use as a model for the development of new more attractive ones.

ISSN: 07 I8-2724. (http://www.jotmi.org) 
Since consumers expressed their preferences in the usage of this new kind of store for clothes, we propose a new immersive fashion store that reflects their interests. Based on the findings, we improved the store to make it more attractive. For instance, due to the consumer's preference in visiting a bigger store in order to have the possibility to visualize a wider amount of products if compared to the traditional points of sale, we enlarged the store, in order to influence the perception of a bigger surface. To achieve this goal, we removed the inners walls that separate the parts of the environment and created one bigger open space (Figure 3).

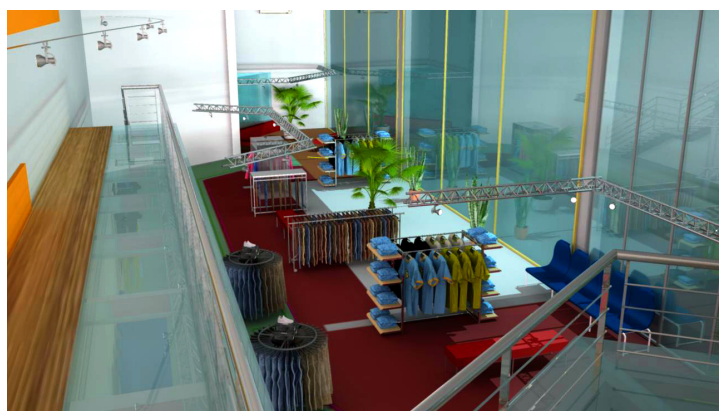

Figure 3:The new store.

Furthermore, we improved the sense of realism by adding plants and furniture and filling the shelves and armchairs (Figure 4).

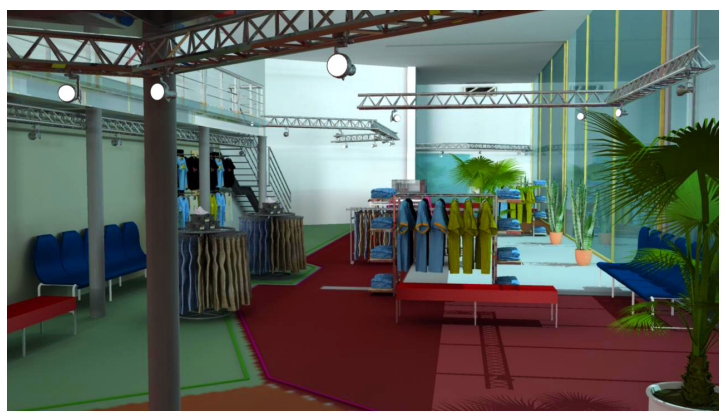

Figure 4: Detail of furniture, products, plants added after consumers suggestions.

\section{Implications for retailers}

Our findings highlight consumers' preferences for big shopping environments, where a large amount of products are displayed. Moreover, they prefer points of sale with areas for relaxing, eating and drinking, which enhance their experience and influence their permanence in the store, even if these areas are not real. The further introduction of plants and flowers makes the store more confortable and realistic. Respondents made some important suggestions for implementing the store according to their expectations as follows: - the space should be enlarged, to give consumer the feel- ing of visit a wider store. Since the environment is based on virtual reality, there are not space constraints;

- plants and furniture should be added to make the store more "realistic";

- inner walls should be removed in order to create a one bigger open space;

- all blanks have to be filled with products. Consumers avoid seeing empty spaces in the stores.

These elements might have the major influence on consumer's choice of store and on their trust in the vendor, with benefits for firm's profitability.

Since the appeal of immersive technologies for consumers, retailers who introduce these ones would attract more consumers and achieve an advantage over the main competitors. In particular, stores with limited space for displaying products (i.e. $70-80 \mathrm{mq}$ ) or which need wider spaces due to the particular sizes or quantity of the products (i.e. furniture or book stores) would take advantages from the use of immersive technologies.

For instance, bookstores and libraries could introduce the immersive tools, which allow integrating projections of 3D trailers or movies sketch realized from the original novels, which are already applied in many 3D cinemas. Therefore, it would be possible to catch interest of a wider consumers audience towards literature.

\section{Conclusions}

According to consumers' viewpoint, we developed a new store based on immersive technologies, by emphasizing the characteristics that make the environment more attractive and appealing such as big shops with many spaces for displaying products, a large amount of items and more information available, as well as some areas for relaxing. We expect that the new points of sale based on our framework for immersive stores will be more effective and will be capable of influencing consumers' shopping mode choice and purchasing decision.

In particular, our analysis highlights to what extent the use of immersive technologies can be an effective tool for innovating, by offering a technological solution able to change the modus operandi of retailing-oriented firms and the relationships with clients.

Since innovation can fail, the new scenario offers a new channel for testing the actual effects of the innovative solution before the effective realization, by involving consumers

ISSN: 07 I8-2724. (http://www.jotmi.org) 
in an entertaining environment. Hence, the innovative store represents both an innovative retail system and a novel tool for supporting the store design process. Furthermore, it enhances the provided products information, by dramatically changing the way products and services are performed.As a consequence, innovation caused by immersive technologies is perceived as an effect of the introduction of an advanced tool in traditional retailing, which seems to be highly appreciated by end-users.

Hence, retailers could introduce immersive technologies for enriching their physical stores, or use them only in the design process, for testing the store before the effective realization. Managers should take into account these tools when designing new stores, in order to meet clients' preferences and needs, with benefits for the quality of the service offered and of the whole retail process.

Since the immersive store has been developed and tested in a university lab, we didn't evaluate the real consumer flows in the store, thus, future works could test the prototype in shopping centres in order to investigate its effect on number of consumers, as well as on their purchasing by investigating both the increasing/decreasing amount of expenditure and the frequency of purchases.

\section{References}

ALGHARABAT, R., Dennis, C. (20I0). 3D product authenticity model for online retail: An invariance analysis. International Journal of Business Science and Applied Management, 5 (3), I4-30.

BAUER, J.C., Kotouc, A.J., Rudolph, T. (in press.). What constitutes a "good assortment"? A scale for measuring consumers' perception of an assortment offered in a grocery category. Journal of Retailing and Consumer Services.

CHEN, L.-D., Tan, J. (2004). Technology Adaptation in E-commerce: Key Determinants of Virtual Store Acceptance. European Management Journal, 22 (I), 74-86.

CHIU, C.-M., Huang, H.Y., Yen, C.-H. (20I0). Antecedents of trust in online auctions. Electronic Commerce Research and Applications, 9, I48-159.

DAVIS, F.D. (1989). Perceived usefulness, perceived ease of use, and user acceptance of information technology. MIS Quarterly, 13, 319-340.

FULLER J., Hutter K., Faullant R. (20II). Why co-creation experience matters? Creative experience and its impact on the quantity and quality of creative contributions. R\&D Management, 4 I (3), 259-273.
HA, S., Stoel, L. (2009). Consumer e-shopping acceptance: Antecedents in a technology acceptance model. Journal of Business Research, 62, 565-57I.

HSIAO, M.-H. (2009). Shopping mode choice: Physical store shopping versus e-shopping. Transportation Research Part E., 45, 86-95.

IQBAL, M., Hashmi M.S.J. (200I). Design and analysis of a virtual factory layout. Journal of Materials Processing Technology, I I8, 403-4I0.

JIN, S.-A.A. (2009). The Roles of Modality Richness and Involvement in Shopping Behaviour in 3D Virtual Stores. Journal of Interactive Marketing, 23 (3), 234-246.

JUGEND D., da Silva, S.L. (20I2). Integration in new product development: case study in a large Brazilian high-technology company, Journal of Technology Management \& Innovation, 7 ( $), 52-63$.

KANG, Y.S., Lee, H. (2010). Understanding the role of an IT artifact in online service continuance:An extended perspective of user satisfaction. Computers in Human Behavior, 26, 353-364.

KIM, J., Fiore, A.M., Lee, H.-H. (2007). Influences of online store perception, shopping enjoyment, and shopping involvement on consumer patronage behaviour towards an online retailer. Journal of Retailing and Consumer Services, 14, 95107.

KORVES, B., Loftus, M. (2000). Designing an immersive virtual reality interface for layout planning. Journal of Materials Processing Technology, 107, 425-430.

LARIA, G., Pantano, E. (20I I). Immersive environments for an advanced technology-based store. Proceedings of 17th International Conference on Networked Computing and Advanced Information Management. IEEE, pp. 2I8-22I.

LEE, K.C., Chung, N. (2008). Empirical analysis of consumer reaction to the virtual reality shopping mall. Computers in Human Behavior, 24, 88- 104.

LEE, J., Han, S., Yang, J. (20I I). Construction of a computersimulated mixed reality environment for virtual factory layout planning. Computers in Industry, 62, 86-98.

LIU, C., Forsythe, S. (20II). Examining drivers of online purchase intensity: Moderating role of adoption duration in sustaining post-adoption online shopping. Journal of Retailing and Consumer Service, 18, I0I-109. 
LUBECK, R.M., Wittmann, M.L., Battistella L.F. (2012). Electronic ticketing system as a process of innovation. Journal of Technology Management \& Innovation, 7 (I), 17-30.

MUMMALANENI, V. (2005). An empirical investigation of Web site characteristics, consumer emotional states and on-line shopping behaviours. Journal of Business Research, $58,526-532$.

NIININEN, O., Buhalis, D., March, R. (2007). Customer empowerment in tourism through consumer centric marketing (CCM). Qualitative Market Research: An International Journal, 10 (3), 265-28I.

OH, S.H., Kim, Y.M., Lee, C.W., Shim, G.Y., Park, M.S., Jung, H.S. (2009). Consumer adoption of virtual stores in Korea: Focusing on the role of trust and playfulness. Psychology \& Marketing, 26 (7), 652-668.

$\mathrm{OH}$, J., Fiorito, S.S., Cho, H., Hofacker, C.F. (2008). Effects of design factors on store image and expectation of merchandise quality in web-based stores. Journal of Retailing and Consumer Services, 15, 237-249.

OLSEN,T. O.,Welo,T. (20II). Maximizing product innovation through adaptive application of user-centered methods for defining customer value. Journal of Technology Management \& Innovation, 6 (4), 172-192.

PANTANO, E., Corvello,V. (2010). Digital contents management for improving consumers' experience. International Journal of Digital Content Technology and its Application, 4 (7), 8-10.

PANTANO, E., Naccarato, G. (20I0). Entertainment in retailing: the role of advanced technologies. Journal of Retailing and Consumer Services, 17 (3), 200-204.

PANTANO E., Viassone M. (in press). Consumers' expectation of innovation: shift retail strategies for more attractive points of sale. International Journal of Digital Content Technology and its Application.

PARKER J.R., Lehmann, D.R. (20I I). When Shelf-Based Scarsity Impacts Consumer Preferences. Journal of Retailing, 87 (2), I $42-\mid 55$.

POLYS, N.F., Kim, S., Bowman, D.A. (2005). Effects of information layout, screen size, and field of view on user performance in information-rich virtual environments. Proceedings of the ACM symposium on Virtual reality software and technology, pp. 48-49.
SANCHEZ, A., Lago A., Ferras, X., Ribera, J. (20II). Innovation management practices, strategic adaptation, and business results: evidence from the electronics industry. Journal of Technology Management \& Innovation, 6 (2).

SCHLOSSER, A.E., Shavitt, S. (2009). The effect of perceived message choice on persuasion. Journal of Consumer Psychology, 19, 290-301.

SMITH, R.P., Heim, J.A. (1999). Virtual facility layout design: The value of an interactive three-dimensional representation. International Journal of Production Research, 37 (17), 394|-3957.

SODERLUND, M., Julander, C.-R. (2009). Physical attractiveness of the service worker in the moment of truth and its effects on customer satisfaction. Journal of Retailing and Consumer Services, 16 (3), 216-226.

TSAI,Y.C., Yeh, J.C. (20I0). Perceived risk of information security and privacy in online shopping: A study of environmentally sustainable products. African Journal of Business Management, 4 (18), 4057-4066.

UDO G.J., Bagchi, K.K., Kirs, P.J. (2010). An assessment of customers' e-service quality perception, satisfaction and intention. International Journal of Information Management, $30,48 I-492$.

VIEIRA, V.A. (2010). Visual aesthetics in store environment and its moderating role on consumer intention. Journal of Consumer Behaviour, 9, 364-380.

VRECHOPOULOS, A.P., O'Keefe, R.M., Doukidis, G.I., Siomkos, G.J. (2004). Virtual store layout: an experimental comparison in the context of grocery retail. Journal of Retailing, 80 (I), I3-22.

WANG, Y.J., Minor, M.S., Wei, J. (20I I). Aesthetic and the online shopping environment: Understanding consumer responses. Journal of Retailing, 87 (I), 46-58. 
J.Technol. Manag. Innov. 2012,Volume 7, Issue 3

ISSN: 07I8-2724. (http://www.jotmi.org)

Journal of Technology Management \& Innovation @ Universidad Alberto Hurtado, Facultad de Economía y Negocios. 